\title{
Clinical and health care aspects of respiratory tract disorders in Poland
}

\author{
Krzysztof Kanecki', Katarzyna Zycinska², Piotr Tyszko' \\ ${ }^{1}$ Department of Health Care, Medical University of Warsaw, Poland \\ ${ }^{2}$ Department of Family Medicine, Medical University of Warsaw, Poland \\ Kanecki K, Zycińska K, Tyszko P. Clinical and health care aspects of respiratory tract disorders in Poland. Ann Agric Environ Med. 2016; 23(1): \\ 125-128. doi: 10.5604/12321966.1196867
}

\section{Abstract}

Introduction. Respiratory diseases constitute a public health priority worldwide. This is related to the increasing exposure to microorganisms, toxic factors, allergens, drugs and smoking, as the most important factors. Increasing costs of health promotion, prevention, diagnosis and treatment of respiratory tract diseases forces the search for effective strategies in the reduction of costs without making a significant impact of these activities on health results. Chronic obstructive pulmonary disease (COPD) is an example of these diseases with increasing incidence, which has few known modifiable factors and absorbs large medical and social costs.

Objectives. The aim of this study is to present the conception of cost driver analysis that could be useful in constructing a good combination of the EBM-based treatment with cost reduction decisions.

Material and methods. Analysis of cost drivers was based on the Global Initiative for Chronic Obstructive Lung Disease (GOLD) guidelines and Polish recommendations of COPD diagnosis and treatment. The proposition of cost reduction strategy in COPD treatment was based on identification of cost drivers in value chain conception.

Results and conclusions. An increasing incidence and treatment costs of COPD force the search for methods of costs reduction in health care. Identifying, evaluating and modifying the cost drivers with use of the value chain conception could be an effective method in achieving these objectives.

\section{- Key words}

respiratory tract disorders, COPD, health care, cost drivers, Poland

\section{INTRODUCTION}

Respiratory diseases are a public health priority worldwide. This is related to growing exposure to microorganisms, toxic factors, allergens, drugs and smoking, as the most important factors. Increasing costs of health promotion, prevention, diagnosis and treatment of respiratory tract diseases force the search for effective strategies of expenses reduction, without a significant impact of these activities on health results. Chronic obstructive pulmonary disease (COPD) is an example of these diseases with increasing incidence, few known modifiable factors and which absorb large medical and social costs. Increasing COPD incidence is a problem for medical institutions and payers of health care services. The progressive, usually irreversible, course of COPD leads to inevitable disability and implies a significant amount of financial resources associated with its treatment. A selfreported COPD prevalence in 2008 was estimated to be $3.3 \%$ in Europe and 3\% in Poland [1]. Among the population of smokers over the age of forty in Poland, airflow limitation was estimated to be about 20-23\% [2]. This disease was the cause of $2.6 \%$ of male deaths and $1.3 \%$ of female deaths in Poland [3]. COPD is the leading cause of morbidity and mortality worldwide, and results in an economic and social burden that is both substantial and increasing $[4,5]$. Exacerbation of the disease is a common cause of hospitalization, accounting for about 120,000 cases of hospital admissions per year in Poland [6]. In Polish studies, it has been reported that the biggest impact on the costs of treatment of COPD exacerbations were hospitalization expenses that were 6-fold higher than

Address for correspondence: Krzysztof Kanecki, Department of Health Care, Medica University of Warsaw, 02-007 Warsaw, Poland

E-mail: kanecki@mp.pl

Received: 18 November 2013; accepted: 26 May 2014 expenses in primary care [7]. In another study, the costs of treatment of COPD exacerbations in a hospital are almost ten times higher than in an outpatient setting [8]. An increasing incidence and treatment costs of COPD force the search for cost reduction solutions in health care.

It has been reported that significant cost drivers in the treatment of COPD exacerbations in Poland were patient age, severity of previous exacerbations of COPD, number of exacerbations in a year, and the coexistence of coronary heart disease [8]. In that article, the main items in costs of hospitalization were incurred in treatment and costs referring to 'a hospital bed'. Among the hospital treatments, the most expensive were antibiotics. The high cost of ambulatory pharmacotherapy were generated by drugs administered in inhalers (more than $20 \%$ of all direct costs). In another study of costs for COPD exacerbation treatment from northern Sweden, the main cost driver in the treatment was hospitalization, the cost of which represented two-thirds of the total costs of the COPD treatment [9]. The study reported that costs varied considerably with the severity of the exacerbation, as well as with the severity of COPD.

\section{OBJECTIVE}

To present the conception of cost drivers analysis that could be useful in constructing a good combination of EBM-based treatment with cost reduction decisions.

\section{MATERIALS AND METHOD}

The conception of cost reduction analysis in the treatment of COPD exacerbations is based on medical guidelines 
and standards, such as the Global Initiative for Chronic Obstructive Lung Disease standards (GOLD) - the generally accepted standards of practice in COPD [10], and Polish recommendations of COPD diagnosis and treatment [11], guidelines for the management of community-acquired respiratory tract infections [12], recommendations for palliative care in chronic lung diseases [13], recommendations for smokers education, and cigarette addiction treatment [14]. These documents were analyzed because they include standards and recommendations based on high levels of evidence, and represent the widely- accepted standards of practice in COPD diagnosis and treatment in Poland.

The method used in the study is analysis of the international and Polish standards, and analysis of the literature on the use of the concept of cost drivers for the optimization of treatment costs.

Cost driver was defined as any factor that causes change in operating costs. The idea of cost drivers in COPD treatment in outpatient care has been widely described in literature $[8,15,16]$. The proposition of cost reduction strategies in COPD was based on value chain conception [17], according to which the health care system and its components could be presented in the form of strings of consecutive, strategically important activities. These activities could be identified, analyzed according to main parts of care system - subjects and processes. Subjects that could be taken in this analysis include patients, medical outpatient and inpatient care, government institutions and payers of medical services. All subjects taking part in health service delivery should be identified at the beginning of analysis. Processes could be defined as the relations among all subjects, especially the patient, services provider, payer, and public institutions. Processes could be defined among subjects and all parts within one subject. Cost drivers could be defined and estimated in any processes among subjects and processes within any subject.

Another purpose of the analysis using the value chain conception is identification valuable and non-valuable processes (activities). The valuable activities create value in the field of health care and are necessary in order to meet the needs of COPD patients, such as disease prevention, health promotion, appropriate diagnosis, treatment and rehabilitation, and cannot be eliminated. Examples of non-valuable activities in health care may be duplication of diagnostic tests by different health care providers, such as GPs and specialists, polypharmacy, and administrative and treatment limitations, which cause iatrogenic effects. These activities should be identified, reduced, eliminated or redesigned to valuable activities.

The next proposition in cost drivers analysis is to divide cost drivers into two analyzed groups. A group of nonmodifiable factors, such as legal and administrative rules, standards and recommendations of treatment, and a group of modifiable factors that could be changed in cost reduction decisions. Accurate differentiation among these factors allows for the effective implementation of proper decisions and avoiding the costs of bad decisions. In the process of decision-making, all relevant subjects should be analyzed according to the creation of costs.

The processes in some subjects of care system could be distinguished by two types of activities: basic and ancillary. In medical organizations, basic actions are non-specific and refer to prevention, treatment to prevent the development of disease, treatment to limit the consequences of disease - including rehabilitation, medical and social care and terminal care. Ancillary activities refer to management, training and supplementary training and research. Ancillary activities form a favourable environment for the implementation of basic tasks and also boosters them.

\section{RESULTS}

GOLD standards and Polish recommendations widely describe the diagnosis and treatment procedures and these activities may be translated in a value chain conception. In this conception, identification of the relevant processes as cost drivers should be made. For example, these factors could be health promotion in COPD, prevention, early identification of high risk patients, early diagnosis, good and adequate treatment introduced in a short time, prevention of complications, and the early treatment of complications. In GOLD standards, COPD exacerbation could be prevented mainly by smoking cessation, influenza and pneumococcal vaccination, education about risk factors, and appropriate therapies. These processes are examples, but not all of them. All these activities should be performed primary in outpatient care in order to avoid the necessity of expensive hospitalization After identification of these relevant processes, they could be evaluated for costs of changing, time needed for change, for needed financial, human or other kinds of resources. That is the base for further strategy of costs reduction.

In this study, making a decision between outpatient and inpatient treatment of patients with COPD exacerbation was chosen as the critical point in the value chain conception. Other decisions about patients with COPD exacerbation could be taken in similar way, according to the value chain conception.

An exacerbation of COPD is an acute event characterized by a worsening of the patient's respiratory symptoms that is beyond normal day-to-day variations and leads to a change in medication [10]. According to the GOLD standards, diagnosis of COPD exacerbation is related to interviews as a basic, valuable and modifiable activity. The GOLD standards directly indicate interviews as the most relevant activity, and indicate other factors as a biomarker or panel of biomarkers that allow a more precise etiologic diagnosis, which would be desirable in the future.

Auxiliary activities could be related to good organization of health service provision. To diagnose COPD exacerbation in a short time, the health care organizations should have the ability to give medical advice in a relatively short time, and the patient should also have the possibility to obtain a medical advice in a short time. All these processes are auxiliary and modifiable, and may significantly shorten the time for medical advice. On the other hand, there should be auxiliary mechanisms to avoid the abuse of medical advice because it does not serve patients and may generate additional costs for health care.

Subjective symptoms reported by patients sometimes need additional examinations for excluding other diseases. Analysis of parameters such as respiratory gas analysis, functional testing and imaging, allow for the earlier implementation of treatment and reduction of the number of hospitalizations and other consequences of exacerbations. These examinations are basic, valuable and necessary because they help in the diagnosis of COPD complications. The GOLD standards 
enumerate tests that may be considered for assessment of the severity of exacerbation (pulse oximetry, chest radiograph, ECG, biochemical tests, presence of purulent sputum). These test are relatively fast to perform in outpatient care, and relevant in taking a decision about hospitalization.

After diagnosing COPD exacerbation, the next step is implementation of the proper treatment. Besides education, elimination of risk factors and other necessary activities, treatment with antibiotics should be considered immediately. COPD exacerbations become more frequent and more severe in advanced stages of the disease [18]. A quick implementation of antibiotics, according to the GOLD standards, helps in the care of the patient and to minimizes costs. GOLD standards and Polish recommendations state when antibiotics should be given to patients with exacerbations of COPD, factors which are exactly indicated and are valuable according to the standards and recommendations. According to GOLD, antibiotics should be given to patients with exacerbations of COPD who have an increase in sputum purulence and increase in dyspnea or sputum volume, or require mechanical ventilation. The choice of antibiotic is modifiable, but should be based on the local bacterial resistance pattern. A few procedures are valuable in outpatient care, such as sputum cultures or procalcitonin III, and are reported to be helpful in decision taking, but they are either time-consuming or too expensive.

Bacteria could be the cause of about $50 \%$ of COPD exacerbations [19]. The antibiotic used in outpatient treatment of infectious exacerbations of COPD should work on S. pneumoniae and $\mathrm{H}$. influenzae and $\mathrm{M}$. Catarrhalis, but the choice of the antibiotic should be based on the local bacterial resistance pattern. Helpful information for constructing a cost reduction strategy is the decision about antibiotics taken at family doctor level or outpatient specialized care, seems to have the same influence on the costs of care. One study showed no significant differences in the costs of care in COPD treatment exercised by pulmonologists, internists and family physicians [20].

The increasing number of patients with diagnosed COPD is a growing problem. The GOLD guidelines highlighted the need for the long-term monitoring of COLD patients and applied treatment. Regular measurements of lungs function in outpatient care and patient symptom self-assessment contribute significantly to the effectiveness of COPD treatment. These procedures may be important components in the prevention of exacerbations. Inadequate control of the disease, lack of patient involvement in treatment or inadequate health education, are examples of significantly important cost drivers. In outpatient care, every procedure indicated in the standards should be performed to diagnose and treat COPD exacerbations.

One of the most important problems in the treatment of COPD exacerbation is a clear differentiation of indications to outpatient and inpatient care. Hospitalization is a good solution for patients in an advanced stage of COPD or exacerbation with complications, but it generates significant costs, and carries the risk of complications of inpatient care. Outpatient care generates less costs, but communications between patient and medical service may be limited by the improper organization of health care. GOLD standards clearly show potential indicators for hospital assessment or admission. In the value chain conception, hospitalization as a cost driver may be one of the most relevant; therefore, the decision about hospitalization should be taken with consideration of data from GOLD.

Other activities that increases the life expectancy of patients with COPD are smoking cessation and home oxygen therapy (DLT) [21] which should be considered in medical treatment. The first line in COPD treatment is the fight against the addiction to cigarette smoking and patient education plays the most important role in prevention.

The definition of COPD exacerbation in GOLD standards and Recommendations of the Polish Society of Lung Diseases about the diagnosis and treatment of COPD are similar, but potential indications for hospital assessment or admission are slightly different, especially according to such indications as frequent exacerbations, older age or insufficient home support. These differences may play an important role in constructing local strategies for costs reduction in the treatment of COPD in outpatient or inpatient care. Interestingly, GOLD and Polish standards clearly indicate when referring the patient for hospitalization should be considered.

Another method for preventing exacerbations of COPD is influenza and pneumococcal vaccinations. It has been shown that exacerbations caused by respiratory viruses are more severe and frequent [22].

Depression may be an independent risk factor for death in patients with exacerbations and in a stable period of the disease [23]. Pharmacological treatment and behavioral techniques should be considered. In contrast to patients with cancer, prediction of the final phase of life is much more difficult in COPD patients [24]. The most important factor that may influence mental health is deterioration of the quality of life. COPD patients could be lonely, with social isolation and lack of integrated care, especially family care or palliative care. These factors may contribute to COPD exacerbation. Rehabilitation and increasing physical activity in these patients are effective ways to improve the quality of life and delay progression of the disease. These factors may be considered in a comprehensive approach to treatment of COPD exacerbations and analysis of cost drivers.

\section{DISCUSSION}

An increasing incidence and treatment costs of respiratory tract diseases force the search for methods of cost reduction in health care. An analysis of cost drivers in the value chain conception is presented in this article on the example of treatment of COPD exacerbations as a method for building a cost reduction strategy. Also presented are examples of cost drivers taken from standards and recommendations. Such an approach for cost reduction strategy is consistent with evidence-based medicine (EBM) and could be widely used in medical practice. In the presented conception, activities based on medical standards and recommendations could be presented in the form of strings of consecutive, strategically important activities. These activities are the basis for building strategy and cannot be eliminated, but they can be modified if such an alternative exists in the standards or recommendations. Auxiliary activities could be implemented in strategy if they do not conflict with the standards or recommendations, and if they are relevant for cost reduction. The presented cost reduction strategy is consistant with EBM-based treatment, and this aspect is the most important in this conception. 
According to EBM-based treatment, it should be highlined that the costs of COPD treatment may vary according to compliance with the GOLD guidelines. The cost observed for patients with stage II of the disease is higher than expected in patients who adhere to treatment, but patients with stage III disease treated according to the GOLD guidelines had significantly higher treatment costs [25].

Improvement in every process (activities), even small, will bring significant improvement in the final results. Hospitals or clinics are parts of a broader value chain within the health care system, but at the same time, they create internal value chains within themselves and their own components.

It is worth noting that the main barriers in cost reduction of COPD treatment may be the problems in organization of the health care system. A heavily-regulated public system with a stringent budget constraint, restricted sub-national government autonomy, a thin private insurance market, heavy out-of-pocket payments, and long waiting lists, generate inequalities in access to outpatient care [26]. The proper cooperation of all organizations, units, and subjects should be involved in the process of costs reduction. Bad decisions in one of these subjects could significantly limit the effectiveness of other institutions engaged in cost reduction. An important conclusion from another article is that the major area for achieving cost savings is the reduction of hospital care [27].

\section{CONCLUSIONS}

1. An increasing incidence and costs of treatment of respiratory tract disorders forces the search for methods of cost reduction in health care.

2. Identifying, evaluating and modifying the cost drivers in value chain conception could be effective methods in achieving these objectives.

3. Medical standards and recommendations could be the base for creation of cost reduction strategy.

The overall conclusion is that identification, estimation and modification of all relevant cost drivers in COPD treatment may be a useful method for improving cost reduction. The strategy of cost reduction in COPD treatment should be based on medical recommendations and standards. The development of information systems may be helpful in cost drivers analysis and application of standards and recommendations at the level of primary health care. Additionally, Information systems are helpful in eliminating duplication of medical procedures in outpatient care. This may open new opportunities for the development of cost reduction strategies.

\section{REFERENCES}

1. ECHI Report. European Community Health Indicators. http:// ec.europa.eu/health/major_chronic_diseases/indicators/index_en.htm (access: 2012.11.16)

2. Zieliński J, Bednarek M, Górecka D. National Program of Early Detection and Prevention of COPD in the years 2000-2002. Pneum Alerg Pol. 2005; 73 (2): 116-121.

3. Kuna P, Pierzchała W, Jankowski M. Astma i POChP w pytaniach i odpowiedziach. Kraków. Med Prakt. 2008.
4. Lopez AD, Shibuya K, Rao C, et al. Chronic obstructive pulmonary disease: current burden and future projections. Eur Respir J. 2006; 27: 397-412.

5. Matters CD, Loncar D. Projections of global mortality and burden of disease from 2002 to 2030. PLoS Med. 2006; 3:e442.

6. National Institute of Public Health - National Institute of Hygiene. The health status of the polish population. http://www.pzh.gov.pl/page/ fileadmin/user_upload/PZH_Raport_2008.pdf (access: 2012.11.13).

7. Jahnz-Różyk K, Targowski T, From S. 2008. Porównanie kosztów leczenia umiarkowanych i ciężkich zaostrzeń przewlekłej obturacyjnej choroby Płuc w Polsce w warunkach ambulatoryjnych i szpitalnych. Pneumonol Alergol Pol. 2008; 76: 426.

8. Jahnz-Różyk K, Targowski T, From S, Faluta T, Borowiec Ł. Koszty leczenia zaostrzeń przewlekłej obturacyjnej choroby płuc w warunkach ambulatoryjnych i szpitalnych w roku 2007. Pol Merk Lek. 2009; 26: 208-14.

9. Andersson F, Borg S, Jansson S, et al. The cost of exacerbations in chronic obstructive pulmonary disease (COPD). Respir Med. 2002; 96: $700-8$.

10. Global Initiative for Chronic Obstructive Lung Disease - GOLD. http:// www.goldcopd.org/uploads/users/files/GOLD_Pocket_May2512.pdf (access: 2012.11.17).

11. Pierzchała W, Barczyk A, Górecka D, Śliwiński P, Zieliński J. Zalecenia Polskiego Towarzystwa Chorób Płuc rozpoznawania i leczenia przewlekłej obturacyjnej choroby płuc. Pneumonol Alergol Pol. 2010; $78,5: 318-347$.

12. Rekomendacje postępowania w pozaszpitalnych zakażenia układu oddechowego. 2010. http://www.antybiotyki.edu.pl/pdf/ RekomendacjeA42009.pdf (Access: 2012.10.23).

13. Jassem E, Batura-Gabryel H, Cofta S, Doboszyńska A, Farnik M, Górecka D, et al. 2012. Recommendation of Polish Respiratory Society for palliative care in chronic lung diseases. Pneumonol Alergol Pol. 2012; 80, 1: 41-64.

14. Zasady Interwencji Antytytoniowej. Kolegium Lekarzy Rodzinnych w Polsce.http://www.klrwp.pl/file/zasady_interwencji_antytytoniowej. pdf (access: 2012.11.1)

15. Halpern M, Mitchell K, Bakst A, Schmier J. The economic impact of acute exacerbations of chronic bronchitis in the United States and Canada: a literature review. J Manag Care Pharm. 2003; 9: 353-9.

16. Tyszko P. Cost drivers in primary care of patients with chronic diseases. Przew Lek. 2010; 2: 188-192.

17. Porter ME. Competitive Advantage: Creating and Sustaining Superior Performance. The Free Press, New York 1998; 33.

18. Vestbo J, Anderson W, Coxson H, Crim C, Dawber F, Edwards L, et al. Evaluation of COPD Longitudinally to Identify Predictive Surrogate End-points (ECLIPSE). Eur Respir J 2008; 31:869-873.

19. Monso E, Ruiz J, Rosell A, Manterola J, Fiz J, Morera J, et al. Bacterial infection in chronic obstructive pulmonary disease: a study of stable and exacerbated outpatients using the protected specimen brush. Am J Respir Crit Care Med. 1995; 152: 1316-20.

20. Strauss M, Conrad D, LoGerfo J, Hudson L, Bergner M. Cost and outcome of care for patients with chronic obstructive lung disease: analysis by physician specialty. Med Care. 1986; 24: 915-24.

21. Anthonisen N., Skeans M, Wise R, Mafreda J, Kanner R, Connett J. Lung Health Study Research Group. The effects of a smoking cessation intervention on 14.5-year mortality: a randomized clinical trial. Ann Intern Med. 2005; 142: 233-239.

22. Seemungal T, Harper-Owen R, Bhowmik A, Moric I, Sanderson G, Message S, et al. Respiratory viruses, symptoms, and inflammatory markers in acute exacerbations and stable chronic obstructive pulmonary disease. Am J Respir Crit Care Med. 2001; 164: 1618-1623.

23. Voogd J, Wempe J, Koeter G, Postema K, Sonderen E, Ranchor A, et al. Depressive symptoms as predictors of mortality in patients with COPD. Chest, 2009; 135: 619-625.

24. Croft M. Palliative care in end-stage COPD. Br J of Gen Pract. 2005; 55: 234-235.

25. Miravitlles M, Sicras A, Crespo C, et al. Costs of Chronic Obstructive Pulmonary Disease in Relation to Compliance With Guidelines. Ther Adv Resp Dis. 2013;7(3):139-150.

26. Boulhol, H. et al. (2012), "Improving the Health-Care System in Poland", OECD Economics Department Working Papers, No. 957, OECD Publishing. http://dx.doi.org/10.1787/5k9b7bn5qzvd-en (access: 2014.03.12).

27. Ruchlin HS, Dasbach EJ. An economic overview of chronic obstructive pulmonary disease. Pharmacoeconomics 2001; 19(6): 623-642. 